\title{
A PRÁTICA PEDAGÓGICA E A CRIAÇÃO DE UM CONTEXTO FAVORÁVEL PARA A APRENDIZAGEM DE CIÊNCIAS NO ENSINO FUNDAMENTAL
}

\author{
Pedagogical practice and the creation of a favorable \\ context for learning in Primary School Education
}

\author{
Cláudia Valentina Assumpção Galian ${ }^{1}$
}

\begin{abstract}
Resumo: Este artigo tem como objetivo identificar, com base em registros de observações de aulas de ciências no Ensino Fundamental II, em uma escola da rede pública estadual do município de Valinhos, SP, se a prática pedagógica pode criar condições que potencializem ou limitem a exigência conceitual no tratamento do conhecimento. As análises foram feitas por meio da comparação com outros estudos sobre práticas favoráveis à aproximação ao conhecimento científico, desenvolvidos sob a mesma perspectiva teórica - a teoria de Basil Bernstein, e, nesse sentido, ficou evidente o quanto a prática pedagógica analisada se distancia do que vem sendo apontado como uma configuração mais adequada, especialmente por não permitir a intervenção dos alunos na determinação dos tempos envolvidos na aprendizagem, e por preservar rigidamente as fronteiras entre os conteúdos científicos, o que acaba criando condições favoráveis à redução do nível de exigência conceitual nas aulas.
\end{abstract}

Palavras-chave: Ensino de ciências. Ensino Fundamental. Prática pedagógica. Basil Bernstein.

\begin{abstract}
The aim of this article was to identify whether pedagogic practice can enhance or limit some conditions of the conceptual demands in the treatment of knowledge. It was the result of observations of science classes in primary school at the public school of Valinhos. The analysis was carried out by comparing with other surveys about advantageous situations to match the development of scientific knowledge to the same theoretical perspective - the Bernstein theory - and, it was evident that the pedagogic practice was far from what is seen as adequate, especially for not allowing student interventions in the learning schedule and for keeping within scientific content borders, which end up creating advantageous condition for reducing the conceptual demand level in classes.
\end{abstract}

Key words: Science teachin. Primary school. Pedagogic practice. Classification. Framing.

\footnotetext{
${ }^{1}$ Departamento de Metodologia do Ensino e Educação Comparada, Faculdade de Educação, Universidade de São Paulo. Avenida da Universidade, 308, Cidade Universitária. São Paulo, SP, Brasil. 05.508-040.

claudiavalentina@usp.br
} 


\section{Introdução}

Este artigo apresenta o resultado de uma pesquisa de doutorado que teve como tema o conhecimento escolar, entendido como o resultado da transformação do conhecimento oriundo de seu campo de produção quando da sua inserção nas condições escolares, notadamente as que se referem ao tempo, espaço e forma de lidar com os saberes.

Desde o início da investigação, percebeu-se que refletir sobre a relevância do conhecimento escolar para a formação dos alunos gera muitos questionamentos, tais como: de que forma os jovens se relacionam atualmente com o conhecimento que é transmitido pela escola ou qual a importância que conferem a esse conhecimento em sua formação. Mas, diante de qualquer questão, permaneceu a certeza de que receber das gerações mais antigas as indicações do que já foi constituído em termos de conhecimento é um direito inalienável das crianças e jovens. E, também, que à escola cabe transmitir uma seleção deste conhecimento que deveria permitir o uso, a compreensão e o questionamento das informações e dos instrumentos disponíveis na sociedade. Deixar de cumprir esta função social, esvazia a escola de seu sentido maior, como indica Sampaio (1998, p. 22), referindo-se à escola pública: "a escola pública faz sentido à medida que consiga realizar seu trabalho específico, de conhecimento e de ampliação de horizontes, de compreensão do mundo".

Muitas pesquisas indicam que os jovens apontam para a crença no poder da educação escolarizada como instrumento de transformação positiva de suas condições de vida (GIOVINAZZO JR., 1999, 2003; MECONI, 2004; OLIVEIRA, 2001; SOUZA, 2003). Mas, para além das possíveis convicções desses jovens em relação à escolarização, o que é oferecido aos alunos submetidos a esse processo? De que forma o conhecimento tem sido tratado nos documentos oficiais, nos materiais utilizados por professores e alunos e nas salas de aula? Com que nível de complexidade tais conhecimentos têm sido abordados nestas instâncias?

Foi no âmbito dessas questões que se inseriu a referida pesquisa, focalizando-as do ponto de vista do ensino da disciplina de ciências e admitindo-se que esse conhecimento deve garantir ao aluno o domínio de instrumentos, habilidades de pensamento e conceitos que o permitam conhecer o mundo que o cerca - em seus aspectos naturais e nas múltiplas intervenções humanas sobre ele - para entender, questionar e marcar sua posição diante do discurso do poder embutido nas práticas sociais em que está inserido, movendo-se na direção de uma sociedade mais justa. Nesta perspectiva, buscaram-se indícios do que se disponibiliza aos alunos para a aprendizagem dessa disciplina, no que se refere ao nível conceitual com que é tratado o conhecimento científico.

A pesquisa teve como principal referência teórico-metodológica a teoria de Bernstein (1996), e incidiu sobre o processo de recontextualização do conhecimento científico para fins de transmissão escolar.

A concepção do autor sobre o papel da teoria na leitura do empírico justificou a sua escolha como referência teórica e metodológica para esta pesquisa. Sua compreensão dos mecanismos de produção, reprodução e transformação culturais e da relação teoria/empiria hoje se perpetua nos estudos de diversos grupos de investigação, notadamente nos trabalhos do Grupo de Estudos Sociológicos de Sala de Aula (ESSA), vinculado ao Centro de Investigação em Educação da Faculdade de Ciências da Universidade de Lisboa. 
Os estudos relacionados ao ensino e aprendizagem de Ciências, desenvolvidos por este grupo, analisam, entre outros temas: textos curriculares (programas e manuais escolares²), práticas pedagógicas, relações entre discursos, sujeitos e espaços, sob um enfoque teórico ligado à teoria de Bernstein.

A pergunta central que norteou a investigação incidiu sobre a transformação que ocorre com o discurso pedagógico oficial, do ponto de vista do nível conceitual de conhecimentos e competências e das relações entre discursos, no seu deslocamento entre os campos da recontextualização e da transmissão. Desta pergunta central, derivaram as seguintes questões de investigação: (1) Como se expressam o nível conceitual de conhecimentos e de competências, o grau de intradisciplinaridade e a relação entre o discurso acadêmico e o não acadêmico em cada instância de recontextualização analisada? (2) Qual a tendência da recontextualização evidenciada entre as instâncias analisadas? (3) Com relação à prática pedagógica, no que se refere à relação entre sujeitos (professor/alunos), o que se evidencia em termos da seleção, sequência, compassamento e critérios de avaliação ${ }^{3}$ ? (4) Em que medida a natureza das relações professor/alunos, que caracteriza a prática pedagógica em sala de aula, potencializa ou limita as tendências da recontextualização encontradas?

O presente artigo focaliza as duas últimas questões de investigação apontadas acima, ou seja, refere-se ao impacto das relações estabelecidas entre os sujeitos na comunicação pedagógica sobre o nível de exigência conceitual sob o qual será tratado o conhecimento científico.

Pela centralidade dos estudos do Grupo ESSA nas escolhas metodológicas realizadas na pesquisa apresentada, destaca-se um exemplo de investigação conduzida por esses pesquisadores, com o objetivo de encontrar características mais favoráveis à aquisição de conhecimento científico e competências investigativas por alunos de diferentes origens sociais. Morais, Neves e Pires (2004) analisaram a prática pedagógica do professor e a aquisição científica das crianças, focando a interação entre a origem social destas, a prática pedagógica e a aprendizagem científica, tendo o nível atingido pelas crianças, nas competências cognitivas complexas, como medida de aquisição.

Nesta investigação, a análise da prática das professoras foi realizada em termos das relações entre sujeitos (professor/alunos), discursos (intradisciplinaridade, interdisciplinaridade e conhecimento acadêmico/não acadêmico) e espaços (espaço do professor/espaço dos alunos).

As pesquisadoras ressaltam, a partir de sua análise, que os resultados indicam que uma prática altamente favorável à aprendizagem das crianças de origens sociais diferentes deve mesclar determinadas características, tais como: fracas fronteiras entre espaços do professor e dos alunos; relações comunicativas abertas entre professor-alunos e alunos-alunos; critérios de avaliação explícitos; fraco compassamento ${ }^{4}$ da aprendizagem; fortes relações intra-

\footnotetext{
${ }^{2}$ Em Portugal, os livros didáticos são denominados manuais escolares.

${ }^{3}$ Seleção, sequência, compassamento e critérios de avaliação são características pedagógicas ligadas ao controle nas relações entre professor e alunos em torno do conhecimento.

${ }^{4} \mathrm{O}$ compassamento se refere à utilização do tempo no processo de ensino-aprendizagem. Um fraco compassamento da aprendizagem significa uma administração mais flexível do tempo nas aulas, visando respeitar os diferentes tempos de aprendizagem dos alunos.
} 
disciplinares; alto nível de exigência conceitual e alto nível de proficiência investigativa (MORAIS; NEVES; PIRES, 2004, p. 86).

Destacam, ainda, com base neste e em outros estudos do Grupo ESSA, de forma bastante sugestiva para o contexto em que se inseriu a pesquisa apresentada, que:

Não é necessário baixar o nível de exigência conceitual para todas as crianças terem sucesso na escola. Aumentar o nível da exigência conceitual é, inclusive, um passo crucial no sentido de que todos devem ter acesso a um nível maior de literacia científica valorizada tanto pela comunidade científica quanto pela sociedade em geral. (MORAIS; NEVES; PIRES, 2004, p. 86)

\section{Escolhas metodológicas}

O levantamento dos dados da pesquisa incidiu sobre três fontes: (1) os Parâmetros Curriculares Nacionais de Ciências Naturais para o Quarto Ciclo do Ensino Fundamental, representando, aqui, a expressão do discurso pedagógico oficial (DPO); (2) o livro didático distribuído à escola pelo Plano Nacional do Livro Didático (PNLD)/2005, fruto da recontextualização do DPO realizada pelas editoras e pelos autores destes materiais, no campo recontextualizador pedagógico ${ }^{5}$, e (3) a prática docente, que evidencia, por sua vez, mais uma instância recontextualizadora, o contexto da transmissão, no campo da reprodução do discurso pedagógico. Os procedimentos de pesquisa adotados foram: a análise documental e a observação de aulas - o primeiro, especialmente para o cálculo do nível de exigência conceitual atingido no trato com o conhecimento científico nos $\mathrm{PCN} / \mathrm{CN}$, no livro didático e nas explicações das aulas observadas; e o segundo, especialmente no tratamento das questões ligadas às relações entre sujeitos nas aulas. Estas últimas questões são tratadas no presente artigo, portanto, a parte da pesquisa aqui descrita utilizou uma metodologia essencialmente qualitativa.

A pesquisa foi realizada em uma escola da rede pública estadual do município de Valinhos, São Paulo, e as três fontes foram analisadas segundo uma metodologia que se baseou nos procedimentos e nos instrumentos criados e aplicados por diferentes autores ligados ao Grupo ESSA. As respostas às questões colocadas por este estudo pretenderam possibilitar uma melhor compreensão do processo de constituição do conhecimento escolar de ciências, bem como trazer alguma contribuição para a discussão acerca dos determinantes sociológicos que podem estar atuando no sentido de enriquecer ou enfraquecer a relação de alunos e professores com este conhecimento. Diante deste objetivo de pesquisa e da preocupação central anunciada acima, e com base no referencial teórico adotado, derivaram duas hipóteses norteadoras da investigação: (1) de que seria possível flagrar e explicitar o processo de recontextualização do conhecimento escolar de Ciências, e (2) de que esse processo evidenciaria uma tendência ao distanciamento em relação à natureza do conhecimento científico e ao rebaixamento do nível de exigência conceitual.

${ }^{5} \mathrm{O}$ livro didático em questão é: CRUZ, D. Ciências \& educação ambiental: $8^{a}$ série, química e física. São Paulo: Ática, 2007.

422

Ciência \&̊ Educação, v. 18, n. 2, p. 419-433, 2012 
A prática pedagógica e a criação de um contexto ...

$\mathrm{Na}$ referida pesquisa, fez-se a opção pela adoção de uma metodologia mista de pesquisa, compreendendo que as formas de investigação quantitativa e qualitativa não são incompatíveis e podem ser utilizadas complementarmente conforme a natureza das questões de investigação, de modo a permitir análises aprofundadas.

A investigação pretendeu evidenciar o que resulta do processo de recontextualização que incide sobre o conhecimento científico selecionado para a transmissão escolar. Uma das características pedagógicas que se pretendeu focalizar foi: (1) a exigência conceitual com que são tratados os conhecimentos e competências científicas nos $\mathrm{PCN} / \mathrm{CN}$, no livro didático e na prática docente. Para esta análise, considerou-se a complexidade de conteúdos e competências e o grau de intradisciplinaridade com que o conhecimento científico é tratado. Tal abordagem permitiu buscar indícios da transformação ocorrida nestas instâncias de recontextualização no que se refere, especialmente, ao componente instrucional do discurso pedagógico (ao "quê" do discurso pedagógico).

Outra via de recontextualização considerada neste estudo foi: (2) as relações entre discursos, especificamente entre discursos dentro da disciplina, e entre o conhecimento acadêmico e não acadêmico, mais uma vez nas três instâncias. Neste caso, a investigação incidiu sobre o "como" do discurso pedagógico.

No micronível da sala de aula, considerou-se mais uma questão referente ao "como" do discurso pedagógico: (3) a relação entre sujeitos, especificamente entre professor e alunos, que se expressa na comunicação pedagógica. Esta análise - da qual trata este artigo - incidiu apenas nesta instância de recontextualização, e visou identificar em que medida a modalidade de prática pedagógica poderia potencializar ou limitar o nível de exigência conceitual, a intradisciplinaridade e o estabelecimento de relações entre conhecimentos acadêmicos e não acadêmicos no tratamento do conhecimento escolar de Ciências.

A Figura 1 permite identificar as fontes e características pedagógicas focalizadas na pesquisa descrita neste artigo.

Figura 1. Fontes e características pedagógicas analisadas.

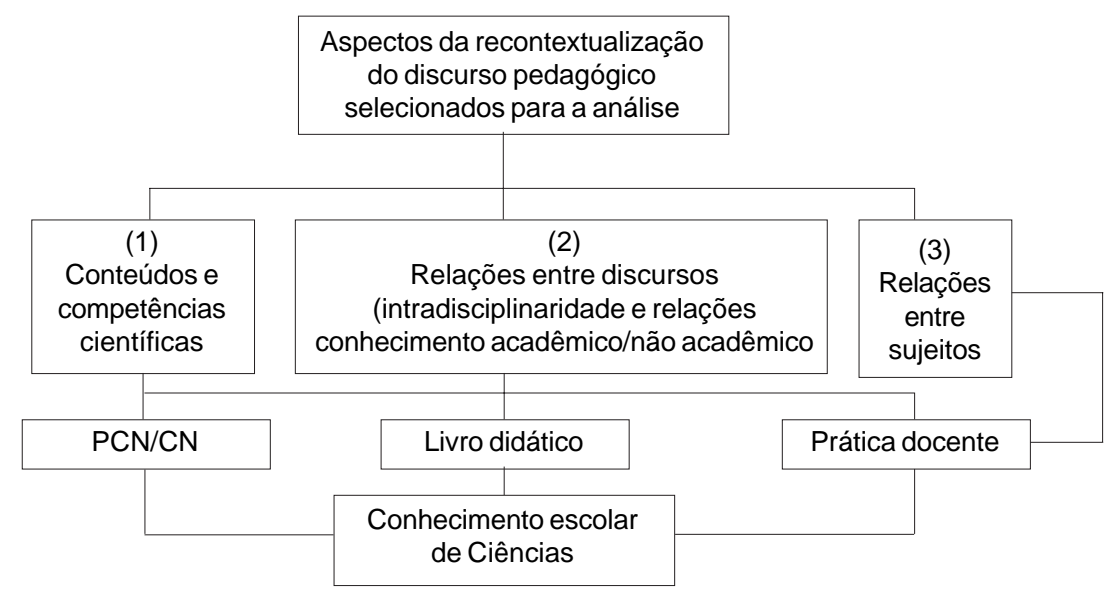

Fonte: Elaborado pela autora 
A análise desenvolvida na pesquisa incidiu sobre os níveis da recontextualização e da transmissão do conhecimento científico, segundo a perspectiva teórica de Bernstein (1996). De forma a evidenciar o nível conceitual com que o conhecimento escolar de Ciências é tratado nas três instâncias de recontextualização, alguns dos aspectos ligados ao "quê" e ao "como" do discurso pedagógico (DP) foram escolhidos a fim de se cumprir com os propósitos assumidos.

A Figura 2 permite identificar os aspectos escolhidos para a análise realizada.

Figura 2. Aspectos considerados para análise.

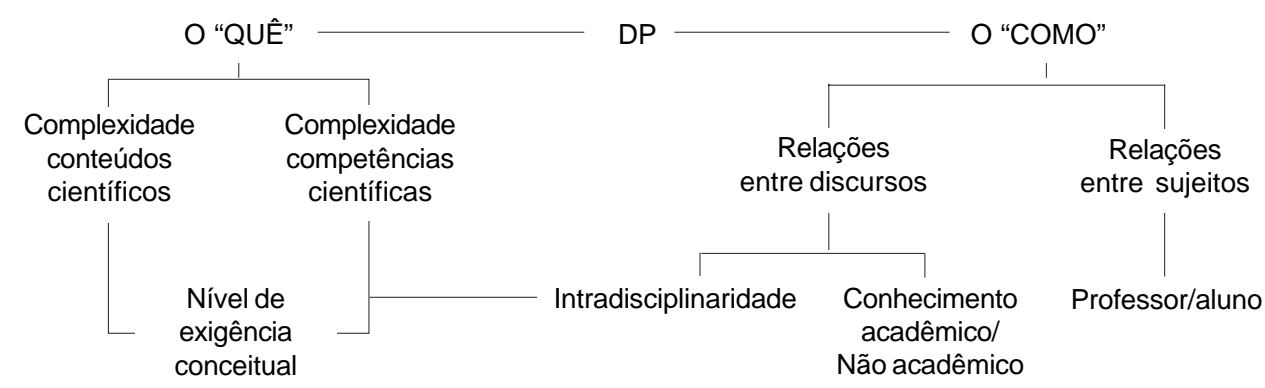

Fonte: Elaborado pela autora

Em relação ao "quê", destacou-se a exigência conceitual com que são abordados os conteúdos, as competências e o grau de intradisciplinaridade envolvidos na aprendizagem da disciplina. Para isso, de cada uma das três instâncias de recontextualização consideradas na investigação - PCN/CN, livro didático e aulas observadas -, foram retirados 15 excertos para análise do grau de intradisciplinaridade, da complexidade das competências científicas e da complexidade dos conteúdos científicos. A partir dos índices parciais para cada uma dessas características, calculou-se o nível de exigência conceitual.

Quanto ao "como" do discurso pedagógico, destacaram-se, para os fins deste estudo: as relações entre discursos - a intradisciplinaridade e a relação conhecimento acadêmico/não acadêmico, nas três instâncias - e, apenas no contexto de sala de aula, as relações entre sujeitos - professor/alunos -, sendo estas últimas o foco deste artigo.

Os conceitos de classificação e enquadramento são muito utilizados na pesquisa, e têm um significado muito específico, representando chaves para o entendimento da teoria de Bernstein, por expressarem a configuração das relações de poder - classificação - e de controle social - enquadramento.

\section{O “como" do discurso pedagógico: relações entre sujeitos}

Foram analisadas, especificamente, as relações discursivas entre professor e alunos que se expressam na comunicação pedagógica. Daí a pertinência de se investigar a prática 
A prática pedagógica e a criação de um contexto ...

pedagógica, e não documentos relativos a ela - aspecto destacado pelo número 3, na Figura 1. Fez-se a opção, portanto, por não se buscar esta característica no PCN/CN nem no livro didático. Entretanto, considerou-se que tais relações são da maior relevância no estabelecimento de um contexto pedagógico favorável ou desfavorável a um elevado nível de exigência conceitual. Estudos como os de Neves e Morais (2001), Morais, Neves e Pires (2004) e outros desenvolvidos pelo Grupo ESSA indicam que a modalidade de prática pedagógica, embora não possa por si só determinar um elevado nível conceitual, pode criar condições para que isto se estabeleça e para a aquisição de conhecimento por todos os alunos. Assim, o que se pretendeu ao focalizar a prática pedagógica foi identificar se ela cria condições que potencializam ou limitam a complexidade com que são tratados os conteúdos e as competências, a intradisciplinaridade e as relações conhecimento acadêmico/não acadêmico que as instâncias de recontextualização analisadas fomentam.

As relações discursivas entre professor/alunos, de acordo com o referencial teórico adotado, referem-se a quatro características pedagógicas que, juntamente com as práticas organizacionais e as regras hierárquicas, constituem o código a ser adquirido no contexto pedagógico de sala de aula: (1) a seleção, que diz respeito às escolhas acerca dos temas a serem abordados, as tarefas/atividades que serão desenvolvidas, aos materiais a serem utilizados, aos aspectos que comporão as sínteses ou às perguntas pertinentes para a aula; (2) a sequência, que trata da ordem com que os temas, as atividades e as sínteses serão realizadas, bem como os momentos mais adequados para as intervenções dos alunos; (3) o compassamento, que se refere ao tempo dedicado às discussões, às explicações e resolução de dúvidas, à realização das atividades, à produção de sínteses, ao registro nos cadernos e aos questionamentos entre professor e alunos em torno do conhecimento, e (4) os critérios de avaliação, que dizem respeito ao grau de explicitação dos conteúdos abordados, do tipo de trabalhos/atividades a serem realizados e do teor das sínteses a serem produzidas (BERNSTEIN, 1996).

Tais relações discursivas expressam as relações de controle que se estabelecem em sala de aula, portanto, dizem respeito ao enquadramento, conceito desenvolvido por Bernstein (1996) e que se refere às relações de controle na comunicação pedagógica. Podem apontar para um controle mais centrado no transmissor (enquadramento forte) ou para um controle mais centrado no adquirente (enquadramento fraco). Para efeito da análise da prática docente, foi utilizada uma escala de quatro graus de enquadramento, que reflete contextos em que o controle está totalmente centrado no professor $\left(\mathbf{E}^{++}\right)$e vai progressivamente passando para um contexto em que o aluno detém, em maior grau, o controle destas características $\left(\mathbf{E}^{--}\right)$.

Dada a especificidade do contexto de sala de aula, para a análise das relações de controle expressas na seleção, sequência, compassamento e critérios de avaliação, foram considerados os registros de observação acumulados pela investigadora ao longo de 20 aulas de uma mesma professora. As impressões que permitiram compor um panorama de como tais características se expressam na prática docente não são passíveis de quantificação - como a que foi realizada em relação aos demais aspectos analisados na pesquisa. Considerou-se impossível, em relação a estes aspectos, escapar de uma visão subjetiva do pesquisador, o que reafirma a opção por uma metodologia mista de investigação, com ênfase no viés qualitativo no que se refere às relações professor-aluno.

Para efeito da análise referente ao grau de intradisciplinaridade, relação entre conhecimentos acadêmicos e não acadêmicos, complexidade das competências e dos conteúdos 
científicos nas aulas, foram analisados os registros das observações de seis aulas, ministradas em duas turmas de $8^{a}$ série, nas quais se abordaram temas ligados ao estudo da Química substâncias e misturas, separações de misturas, ligações químicas. Tais análises focalizaram as explicações da professora e suas sínteses registradas na lousa. A partir de excertos desses registros, foi calculado o nível de exigência conceitual atingido nas aulas observadas (GALIAN, 2011).

Ao se tratar das relações professor/alunos, as características de seleção, sequência, compassamento e critérios de avaliação foram identificadas nos seguintes indicadores (que reúnem determinadas situações de sala de aula): (1) Exploração/discussão dos temas em estudo, (2) Trabalhos/atividades a realizar, (3) Elaboração de sínteses, (4) Perguntas dirigidas à turma, (5) Perguntas dos alunos, e (6) Registros no caderno.

A análise de tais características pedagógicas na comunicação fez referência a uma escala de quatro graus de enquadramento. À centralização do controle destes aspectos pedagógicos nas mãos do professor, corresponde um enquadramento forte. $\mathrm{O}$ enfraquecimento do enquadramento ocorre na medida em que este controle passa a ser exercido pelos alunos. A utilização de um instrumento com uma escala de correspondência entre as unidades de análise e quatro graus da escala pretendeu revelar a configuração do controle destes aspectos na comunicação pedagógica em estudo.

\section{A professora e suas aulas}

A observação de vinte aulas de uma mesma professora permitiu identificar um tipo de prática docente cuja descrição visou enriquecer análises acerca do nível de exigência conceitual assumido e o caráter das relações entre sujeitos estabelecidas neste contexto de transmissão/aquisição do conhecimento escolar de Ciências.

$\mathrm{Na}$ ocasião do levantamento de informações para a realização desta pesquisa, a professora estava nos últimos anos do exercício do magistério. No final de 2007, aposentou-se. Portanto, tratava-se de uma professora experiente, respeitada pela coordenadora pedagógica que indicou à pesquisadora que acompanhasse as suas aulas, por se tratar da "melhor professora da escola" - e pelos alunos, que mantinham, em suas aulas, um comportamento mais disciplinado do que em outras aulas observadas pela pesquisadora.

Todas as suas aulas começavam com o controle da frequência e da realização das tarefas de casa. Para esta última atividade, despendia um tempo considerável, uma vez que olhava caderno por caderno e os carimbava, para que os pais pudessem acompanhar - e assinar - a conduta dos filhos em relação às atividades escolares. Nestes momentos, também verificava os carimbos e as provas assinadas pelos pais.

Nas aulas, não se estendia ao tecer comentários sobre a conduta ou sobre o rendimento escolar de seus alunos. Quando isto acontecia, fazia-o por meio de poucos e breves comentários, nos quais buscava enfatizar a responsabilidade que estes e seus pais devem ter para com a vida escolar. Da mesma forma, mostrava-se sempre muito responsável, não adiando a entrega de tarefas ou a realização de avaliações, e entregando, em prazo muito reduzido, todos os materiais dos alunos por ela corrigidos.

Seus registros na lousa consistiam de: (1) indicações sobre o que seria feito na aula no caso de se tratar de uma aula no laboratório ou na sala de vídeo; (2) registros de definições 
- bastante sucintas, esquemáticas, e seguidas da indicação das páginas do livro didático nas quais se encontrava o assunto abordado - ou (3) respostas elaboradas durante a correção de exercícios realizados pelos alunos - embora, mais frequentemente, a correção tenha sido feita apenas oralmente, com a professora ditando as respostas para os alunos.

Suas explicações/explorações do conteúdo seguiam a ordem estabelecida pelo livro didático, embora ela não recorresse a ele durante a aula, exceto para ler as questões que iria corrigir ou para indicar alguma figura que poderia auxiliar a compreensão do tema de estudo. A estas situações de exploração do conteúdo, imprimia um ritmo muito acelerado, falando rapidamente e fazendo perguntas para a turma, sem esperar mais do que poucos segundos para, ou dar a resposta ela mesma, ou confirmar a resposta de algum aluno, por vezes repetindo-a, apressadamente, para o restante dos alunos. As correções de exercícios também seguiam este ritmo, sendo que o pouco diálogo que estabelecia com os alunos, nessas ocasiões, se restringia a algumas frases curtas dirigidas a um pequeno grupo de alunos, sentados nas fileiras da frente, num tom de voz inaudível para os que estivessem sentados no fundo da classe, como costumava estar a pesquisadora.

Realizava com regularidade avaliações de aprendizagem, ao final de cada seção estudada. Os instrumentos de avaliação que produzia eram cuidadosamente preparados e consistiam, na sua maioria, de três partes: (1) um texto, seguido de questões interpretativas de múltipla escolha; (2) questões de associação de colunas ou de preenchimento de lacunas - por vezes, seguidas de uma pequena lista de palavras na qual os alunos deveriam escolher a que melhor preenchesse as lacunas - e, por fim, (3) perguntas sobre o assunto em questão. Vale destacar que o nível de exigência de tais instrumentos de avaliação mostrou-se bastante baixo, com a mobilização de competências e conteúdos científicos de menor nível de abstração.

Enfim, em sua prática docente, a professora revelou uma grande preocupação com o controle do cumprimento das tarefas escolares - tanto as suas quanto as dos alunos e pais. Não parece plausível que ela não cumprisse todo o conteúdo programático previsto para o ano - o que pode ser um dos elementos para o reconhecimento de seus méritos pela coordenação pedagógica e, mesmo, pelos alunos e, provavelmente, pelos pais. Também não se pode negar sua dedicação ao preparo e execução de suas aulas, que, embora fossem, na maior parte das vezes, expositivas, também revelavam a sua busca por alternativas para a abordagem dos temas em estudo. Assim, fez uso de vídeos e de atividades no laboratório e trouxe, em algumas ocasiões, textos retirados de fontes diversas, abrindo a possibilidade de entrada do conhecimento científico por outras vias, além do livro didático em uso.

Também cumpre destacar que a professora mostrou-se bastante dedicada a deixar claro o que esperava de cada aula, de cada atividade, de cada avaliação realizada. Todos os passos a serem dados na realização de qualquer atividade em suas aulas, bem como os critérios que utilizaria para avaliar a participação dos alunos foram cuidadosamente estabelecidos por ela. Deve-se também registrar que, nas relações estabelecidas em suas aulas, identificou-se seu posicionamento hierárquico claro e bastante respeitoso para com os alunos.

$\mathrm{Na}$ interação com o conhecimento, entretanto, garantiu poucas oportunidades de interferência por parte dos alunos, especialmente no que se refere ao tempo disponibilizado para suas questões ou comentários. Além da pouca participação desses jovens na interação professor-conhecimento-aluno, durante as explicações, o conhecimento era trazido com tamanha urgência, num ritmo tão acelerado, que dificilmente eles poderiam ter clareza sobre o que 
entendiam ou não sobre o que estava sendo abordado. Tampouco se pode pensar, diante de tamanha pressa, no desenvolvimento progressivo de habilidades de pensamento minimamente mais complexas, o que parece ter resultado na restrição ao desenvolvimento das capacidades de aquisição de informações que não permitem, isoladamente, acessar os grandes temas unificadores da Ciência. Esta situação ainda se mostra mais desfavorável ao se pensar naqueles alunos que só contam com a escola para proporcionar as condições para o desenvolvimento de meios para acessarem o "conhecimento poderoso", na concepção de Young $(2007)^{6}$.

\section{As relações entre sujeitos nas aulas observadas}

Para a análise das relações professor-alunos que se estabeleceram nas aulas observadas, foram destacadas as relações de controle que prevalecem na definição das seguintes características pedagógicas: (1) seleção, (2) sequência, (3) compassamento e (4) critérios de avaliação. Para tal, os instrumentos de pesquisa adaptados para este fim serviram para orientar a análise dos registros das vinte aulas observadas, no sentido de compor um panorama geral da forma assumida por estas características na prática docente em questão. Foram consideradas, de forma diferenciada de acordo com a característica pedagógica analisada, as seguintes seções das aulas: (1) Exploração/discussão dos temas em estudo, (2) Trabalhos/atividades a realizar, (3) Elaboração de sínteses, (4) Perguntas dirigidas aos alunos, (5) Perguntas dos alunos, e (6) Tempo destinado à realização das atividades ou aos registros nos cadernos.

\section{Seleção}

$\mathrm{Na}$ definição do conteúdo a ser transmitido, nos momentos de exploração/discussão dos temas em estudo, não se pôde identificar qualquer interferência por parte dos alunos: o controle em relação à escolha do que será estudado recai totalmente sobre a professora, sendo ela que indica os temas e levanta os problemas, não aceitando temas selecionados pelos alunos.

$\mathrm{Na}$ indicação dos trabalhos/atividades a realizar, estes são selecionados, estruturados e orientados pela professora, também sem qualquer participação dos alunos e a definição das atividades a serem realizadas em aulas também recai unicamente sobre a professora.

Ao elaborar suas sínteses, é a professora quem seleciona os aspectos que considera mais importantes, não havendo espaço para indicações dos alunos.

Em relação às perguntas dos alunos, a professora seleciona para responder apenas aquelas que estiverem diretamente relacionadas com o assunto que acabou de explorar.

Portanto, em relação a esta característica pedagógica, pode-se afirmar que, nas aulas observadas, o enquadramento é muito forte $\left(\mathrm{E}^{++}\right)$, com o controle claramente localizado nas mãos da professora.

${ }^{6}$ Young (2007, p. 1294) diferencia o "conhecimento dos poderosos", ligado aos detentores do poder em uma dada sociedade, do "conhecimento poderoso", que visa "fornecer explicações confiáveis ou novas formas de se pensar a respeito do mundo". 
A prática pedagógica e a criação de um contexto ...

\section{Sequência}

Em suas aulas, a professora explora os temas/problemas segundo uma ordem que não é alterada, mesmo que haja intervenções dos alunos. É ela quem define esta ordem de apresentação dos temas.

Também os trabalhos/atividades realizados seguem uma ordem definida pela professora, sem qualquer possibilidade de alteração em função dos alunos.

Os momentos de síntese dos aspectos mais importantes abordados em aula são também determinados exclusivamente pela professora. Entretanto, ao surgirem questões dos alunos, a professora interrompe de imediato a sequência que estava a seguir e responde as questões apresentadas, sem se estender na resposta e desde que estejam relacionadas ao tema em discussão.

Assim, o enquadramento, no que se refere à característica pedagógica em questão, também é muito forte de maneira geral, restando alguma possibilidade de interferência dos alunos na determinação da sequência estabelecida pela professora por meio dos questionamentos que fazem.

\section{Compassamento}

$\mathrm{Na}$ exploração/discussão dos temas, a professora não aprofunda nem repete situações já tratadas. Em algumas situações, indica que determinado ponto já foi estudado anteriormente, situando o capítulo do livro que trata de tal ponto, mas não volta a explicar o que já foi abordado.

$\mathrm{Na}$ realização dos trabalhos/atividades, a professora não marca o tempo destinado a sua execução, mas, durante a realização dos mesmos, pressiona os alunos para terminarem as tarefas. Em algumas situações, admite prolongamentos justificados.

Ao elaborar suas sínteses, a professora indica os aspectos mais importantes, sem permitir questões ou interrupções.

Ao dirigir perguntas para a turma, a professora dá, imediatamente, a resposta ou passa para outra pergunta, caso os alunos não respondam.

A professora responde imediatamente às dúvidas de alguns alunos, especialmente os que estão mais próximos a ela, mas não repete as explicações dadas. Muitas vezes, estas respostas são dadas em um volume de voz muito baixo, não constituindo uma abertura de discussão para a classe toda.

Não é estabelecido o tempo que os alunos têm para passar para o caderno os registros da lousa, mas a professora pressiona-os para que o façam com rapidez. Mesmo assim, admite pequenos prolongamentos devidamente justificados.

De uma forma geral, em relação ao compassamento, o enquadramento também é muito forte, com alguma abertura para interferência por meio de questionamentos formulados pelos alunos. Entretanto, esta pequena abertura reduz-se, na prática, em função da rapidez com que são respondidas as questões e do caráter particular que estas situações de "breve" diálogo acabam por assumir. 


\section{Critérios de avaliação}

Durante as explicações/discussões dos temas, a professora não se alonga em muitos pormenores nem em ilustrações referentes ao assunto abordado, registrando, na lousa, apenas algumas frases ou palavras relacionadas com o tema/problema em estudo, para que componham os registros nos cadernos.

Nos momentos de indicação do tipo de trabalho/atividade que os alunos vão realizar, a professora especifica todos os procedimentos a serem adotados, ficando claro, para os alunos, o que deve ser feito.

As sínteses são apresentadas oralmente, pela professora, sem que haja diálogo com os alunos, sendo, ao mesmo tempo, registradas, na lousa, algumas frases ou palavras para compor os registros dos cadernos.

Assim, em relação ao estabelecimento dos critérios de avaliação, verifica-se um enquadramento muito forte ao se considerar a especificação dos procedimentos a serem adotados na realização das atividades. Entretanto, no que se refere às sínteses das explorações/ discussões dos temas, há um enfraquecimento do enquadramento, com uma definição menos clara do que é relevante ou não em termos do conhecimento tratado nas aulas.

\section{Considerações finais}

Diante do exposto, pode-se afirmar que a prática docente analisada assume uma configuração de controle fortemente centralizado na professora, tanto no que se refere à seleção e à sequência dos temas tratados em aula, quanto às definições do tempo destinado para as situações de exploração/discussão destes temas, interações com os alunos em torno do conhecimento e realização de atividades durante as aulas. Também se pode destacar a força do controle da professora sobre a especificação do que é esperado dos alunos em termos de procedimentos a serem adotados na realização dos trabalhos/atividades a serem realizados, tanto em classe quanto em casa. No entanto esta clareza dos critérios de avaliação se perde quando se trata da elaboração das sínteses dos temas estudados.

Sobre a prática docente analisada na pesquisa apresentada, cumpre apontar que ela revelou aspectos que potencializam o rebaixamento do nível de exigência conceitual das aulas de ciências - hipótese anteriormente apresentada e confirmada na pesquisa. O processo de transmissão/aquisição que se estabelece nas aulas envolve a participação dos alunos como ouvintes e executores de tarefas, aos quais não cabe qualquer influência na decisão sobre os assuntos que serão abordados ou sobre a sequência de abordagem, num enquadramento forte da seleção e da sequência, ou seja, com as decisões, nestes âmbitos, centralizadas na figura da professora. Além disso, a eles não são garantidas oportunidades de confrontarem suas explicações prévias às trazidas pela professora, nem tampouco estabelecerem pausas ou retornos durante a transmissão do conteúdo, também configurando um enquadramento forte do compassamento, com as decisões centralizadas unicamente na professora no que se refere à administração do tempo no processo de aprendizagem. Sem oportunidades de se depararem com os próprios erros e avançarem para uma compreensão mais ampla, a grande referência que os alunos têm sobre o seu processo de aprendizagem consiste nas notas obtidas nas situações de 
avaliação planejadas e executadas pela professora. Neste sentido, cabe, aqui, destacar a importância de se criarem condições para a elaboração de explicações pelos alunos e para o confronto com o próprio erro, fazendo referência às ideias de Bachelard (1996, p. 297): “já que não há operação objetiva sem a consciência de um erro íntimo e primeiro, devemos começar as lições de objetividade por uma verdadeira confissão de nossas falhas intelectuais". São estas as oportunidades para que se realizem as necessárias rupturas entre as explicações trazidas de sua experiência anterior e as novas formas de considerar os fenômenos estudados.

Aos alunos, ficam claros os procedimentos que devem executar e a forma pela qual serão avaliados, num enquadramento forte dos critérios de avaliação, ou seja, com a professora esclarecendo o que espera que os alunos cumpram, embora as relações entre os conteúdos que aprendem e entre estes e os que já traziam consigo não sejam esclarecidas. Assim, a prática docente parece valorizar mais o "fazer" do que o "conhecer", numa busca pelo desenvolvimento de habilidades e competências que prescinde de uma base de conhecimentos relevantes. Ao pensar no processo de ensino que levará a cabo em suas aulas, a professora desconsidera o processo de aprendizagem dos alunos, especialmente ao estabelecer um compassamento que imprime um ritmo muito acelerado para o tratamento do conhecimento, como se os tempos de aprendizagem pudessem ser os mesmos para todos os alunos.

As características de tal prática docente acabam por reforçar o rebaixamento do nível de exigência conceitual encontrado no processo de recontextualização acompanhado na pesquisa apresentada, uma vez que, em suas escolhas, a professora opta por lidar com uma fração do conhecimento científico apresentada de forma fragmentada e diretamente ligada ao contexto, na tentativa de garantir que todos os alunos aprendam o que consta dos planos curriculares e que será objeto de avaliação pelos sistemas oficiais de avaliação do Ensino Básico. Por trás dessas escolhas, podem estar atuando diversos fatores, tais como: as questões ligadas ao controle da disciplina em turmas numerosas; o uso de livros didáticos que apontam nesta mesma direção de tratamento do conhecimento científico; a necessidade de abordar grande quantidade de conteúdos em pequenos espaços de tempo e questões ligadas à formação da professora.

Acerca da formação dos professores, vale destacar que se admite que um professor bem formado pode, sim, estabelecer, por exemplo: (1) uma relação mais rica com um livro didático empobrecido, (2) formas de relacionar o conhecimento acadêmico e o não acadêmico, ou (3) uma configuração das relações entre sujeitos - seleção, sequência, compassamento e critérios de avaliação - mais favorável à aprendizagem, de forma a "virar" a relação com o conhecimento científico no sentido de ampliar os horizontes de compreensão de mundo dos alunos. Mas, não se pode ignorar as dificuldades estruturais que marcam os processos de formação dos professores no Brasil, e, diante disso, questiona-se quanto a oferta de um material didático empobrecido, no que se refere ao estabelecimento de relações mais abrangentes dentro da Ciência, a falta de aprofundamento na discussão sobre as relações entre modalidades diferentes de conhecimento e o despreparo ofertado pelos cursos de formação no que se refere às questões da prática não reforçam este quadro precário, apontando para a estagnação e para o bloqueio do acesso a formas de pensamento mais complexas.

Acompanhou-se, nesta pesquisa, um processo de recontextualização do conhecimento científico que assumiu um caráter de redução, de perda conceitual acentuada em relação ao saber de onde provém o discurso instrucional das Ciências Naturais. Entretanto, a afirmação 
da hipótese de pesquisa não significa que se toma tal configuração como uma sentença da qual não se pode escapar. Fica a certeza de que este é um caminho de recontextualização, não o único, e, decerto, não o melhor. Aceito o fato de que a escola lida com uma fração do conhecimento científico transformada, de modo a constituir uma disciplina escolar, e que, portanto, na escola não se faz Ciência, afirma-se a possibilidade de se ter como meta um processo de recontextualização - e o conhecimento escolar dele resultante - que assuma um sentido de explicitação das relações entre os conteúdos estudados e de priorização do desenvolvimento de competências científicas e conteúdos científicos mais complexos.

Um meio de se manter um nível mais elevado de exigência conceitual do conhecimento escolar de ciências sugerido no movimento de análise dos dados da pesquisa é o cuidado com a prática docente. Alguns estudos desenvolvidos no âmbito do Grupo ESSA procuraram identificar características desta prática que seriam altamente favoráveis à aprendizagem de crianças de origens sociais diversas. Em relação às que foram analisadas nesta pesquisa - as relações entre sujeitos (professor-alunos) relativas ao estabelecimento da seleção, sequência, compassamento e critérios de avaliação - tais estudos apontam para a seguinte configuração como a mais favorável à aprendizagem: (1) explicitação clara dos critérios de avaliação, num enquadramento forte, ou seja, com a centralização deste aspecto na figura do professor, (2) fraco compassamento da aprendizagem, num enquadramento fraco, ou seja, com a garantia da possibilidade de intervenção dos alunos na determinação dos tempos destinados à aprendizagem, (3) ênfase nas relações intradisciplinares, numa classificação fraca, ou seja, com a ênfase no estabelecimento de relações entre os conteúdos científicos, e (4) alto nível de exigência conceitual. Neste sentido, fica evidente quanto a prática docente analisada nesta investigação se distancia de tal configuração, especialmente no que se refere ao compassamento - de enquadramento muito forte, no caso analisado, ou seja, sem abertura de possibilidades de intervenção dos alunos na determinação dos tempos envolvidos na aprendizagem - e à intradisciplinaridade - de classificação igualmente forte, ou seja, com forte preservação das fronteiras entre os conteúdos científicos -, o que acabou criando condições favoráveis à redução do nível de exigência conceitual nas aulas.

Vale lembrar que a pesquisa descrita, uma vez que não configura um estudo de largo espectro, não pode ter seus resultados transferidos a outras situações, no sentido de efetuar uma grande generalização; eles acabam por se limitar a este caso específico, inclusive, representando a prática de uma professora no interior da escola - prática que, certamente, pode se diferenciar de outras tantas que se configuram nesta mesma escola. Entretanto, é possível inferir a representatividade destes resultados, uma vez que confirmam e ajudam a compreender um processo de empobrecimento do conteúdo do ensino que não constitui qualquer surpresa para quem discute a educação no Brasil. 
A prática pedagógica e a criação de um contexto ...

\section{Referências}

BACHELARD, G. A formação do espírito científico. Rio de Janeiro: Contraponto, 1996.

BERNSTEIN, B. A estruturação do discurso pedagógico: classes, códigos e controle. Petrópolis: Vozes, 1996.

CRUZ, D. Ciências \& educação ambiental: $8^{a}$ série, química e física. São Paulo, Ática, 2007.

GALIAN, C. V. A. A recontextualização e o nível de exigência conceitual do conhecimento escolar. Educação \& Pesquisa, vol. 37 , n. 4, p. 763-777, dez. 2011.

GIOVINAZZO JR., C. A. A produção acadêmica sobre a educação escolar do aluno-adolescente: 1981-1995. 1999. 131f. Dissertação (Mestrado em Educação) Pontifícia Universidade Católica de São Paulo, São Paulo, 1999.

A educação escolar segundo os adolescentes: um estudo sobre a relação entre a escola e seus alunos. 2003. 2v. Tese (Doutorado em Educação) - Pontifícia Universidade Católica de São Paulo, São Paulo, 2003.

MECONI, S. A escola na visão de alunos de ciclo II do ensino fundamental. 2004. 123f. Dissertação (Mestrado em Educação) - Pontifícia Universidade Católica de São Paulo, São Paulo, 2004.

MORAIS, A. M.; NEVES, I. P.; PIRES, D. The "what" and the "how" of teaching and learning: going deeper in a sociological analysis and intervention. In: MULLER, J.; DAVIES, B.; MORAIS, A. (Ed.). Reading Bernstein, researching Bernstein. London: Routledge \& Falmer, 2004. p. 75-90. Disponível em: < http://web.uct.ac.za/depts/educate/download/ readingbernstein04.pdf>. Acesso em: 21 jul. 2010.

NEVES, I.; MORAIS, A. M. Texts and contexts in educational systems: studies of recontextualising spaces. In: MORAIS, A. et al. (Ed.). Towards a sociology of pedagogy: the contribution of Basil Bernstein to research. New York: Peter Lang, 2001. p. 223-249.

Disponível em: < http://essa.ie.ul.pt/ficheiros/artigos/livros/

2001_textsandcontextsineducational.pdf>. Acesso em: 10 fev. 2010.

OLIVEIRA, R. M. M. A. Na escola se aprende de tudo...: (aprendizagens escolares na visão dos alunos). 2001. Tese (Doutorado em Educação) - Centro de Educação e Ciências Humanas, Universidade Federal de São Carlos, São Carlos, 2001.

SAMPAIO, M. M. F. Um gosto amargo de escola: relações entre currículo, ensino e fracasso escolar. São Paulo: EDUC, 1998.

SOUZA, R. M. Escola e juventude: o aprender a aprender. São Paulo: EDUC, 2003.

YOUNG, M. Para que servem as escolas? Educação \& Sociedade, Campinas, v. 28, n. 101, p. 1287-1302, 2007. Disponível em: <http://www.scielo.br/pdf/es/v28n101/ a0228101.pdf>. Acesso em: 15 jul. 2010.

Artigo recebido em 01/08/2011. Aceito em 23/02/2012. 